\title{
What the surgeon needs to know about percutaneous coronary intervention treatment of chronic total occlusions
}

\author{
Satoru Mitomo ${ }^{1,2}$, Ozan M. Demir ${ }^{1,2,3}$, Antonio Colombo ${ }^{1,2}$, Sunao Nakamura ${ }^{4}$, Alaide Chieffo ${ }^{1,2}$ \\ ${ }^{1}$ Unit of Cardiovascular Interventions, IRCCS San Raffaele Hospital, Milan, Italy; ${ }^{2}$ Vita-Salute San Raffaele University, Milan, Italy; ${ }^{3}$ Department of \\ Cardiology, Imperial College Healthcare NHS Trust, London, UK; ${ }^{4}$ Department of Cardiology, New Tokyo Hospital, Chiba, Japan \\ Correspondence to: Alaide Chieffo, MD, IRCCS. San Raffaele Scientific Institute, Via Olgettina 60, 20132 Milan, Italy. Email: chieffo.alaide@hsr.it.
}

\begin{abstract}
Chronic total occlusion (CTO) accounts for 10-20\% of lesions identified in coronary artery disease (CAD) patients. CTO percutaneous coronary intervention (PCI) is one of the most challenging of lesion subsets due to its technical difficulty, requiring specific operator expertise and equipment. There has been increased interest on CTO PCI evolving with the development of novel techniques and dedicated devices. Furthermore, in order to effectively and systematically utilize these techniques and devices, CTO PCI algorithms have been established. All of these developments have resulted in procedural success rates increasing to approximately $90 \%$. In this review, we outline the evidence base for CTO PCI, conventional and contemporary CTO PCI techniques, CTO algorithms and outline integrated management strategies between cardiac surgeons and interventional cardiologists.
\end{abstract}

Keywords: Percutaneous coronary intervention (PCI); chronic total occlusion (CTO); technique; device; algorithm

Submitted Feb 14, 2018. Accepted for publication May 28, 2018.

doi: $10.21037 /$ acs.2018.06.04

View this article at: http://dx.doi.org/10.21037/acs.2018.06.04

\section{Introduction}

A chronic total occlusion (CTO) is defined as a $100 \%$ stenosis with thrombolysis in myocardial infarction (TIMI) of 0 flow for $\geq 3$ months (1). CTO remains one of the most challenging interventions performed by the interventional cardiologist, often referred to as "the last frontier". It is associated with significant challenges, especially regarding lesion crossing [i.e., compared to non-CTO percutaneous coronary intervention (PCI)]. There has been increased interest around CTOs in the last few years, coupled with CTO PCI rapidly evolving, with the development of novel techniques (anterograde and retrograde approaches, wire manipulations techniques, and so on) and equipment (improved dedicated CTO guidewires, microcatheters, CTO balloons, and coronary stents). Until recently, the prevalence of CTO was poorly defined; contemporary multicenter observational studies have elucidated this important issue. A Canadian multicenter registry of 14,439 patients who underwent coronary angiography identified at least 1 coronary CTO in 2,630 (18.2\%) patients (2).
The U.S. Department of Veterans Affairs Clinical Assessment Reporting and Tracking program registry of 111,273 patients revealed 29,399 (26.4\%) CTO; 42.9\% right coronary artery (RCA) CTOs, $24.3 \%$ left anterior descending artery (LAD) CTOs and $16.5 \%$ left circumflex CTOs (3). However, despite the prevalence of CTOs, most lesions undergo PCI in only $6-22 \%$ of cases $(2,4)$. This may be explained by the scepticism regarding the real clinical benefit from revascularization of CTO, combined with historically low success rates and high complication rates. However, procedural success $(82.9 \%$ to $92.9 \%)$ and adverse event rates of contemporary CTO PCI in high volume centres with dedicated operators is favourable (5-8).

Due to the high prevalence of CTOs in patients undergoing coronary angiography, improvement in technical and procedural success rates and combination with low adverse event rates, we expect CTO PCI numbers to increase significantly over the next few years. Hence, it is vital that cardiac surgeons are aware of contemporary techniques, success rates and associated complications when called up on to assist in management of CTO PCI complications. 


\begin{tabular}{|c|c|c|c|c|}
\hline Yang et al. (18) & 1,066 & $\begin{array}{l}48.5 \text { months } \\
\text { (median) }\end{array}$ & - & $\begin{array}{l}8.3 \% \text { vs. } 5.8 \% \\
(H R 1.57 ; 95 \% \mathrm{Cl}, 0.91-2.72, \mathrm{P}=0.11)\end{array}$ \\
\hline Jang et al. (19) & 738 & $\begin{array}{l}42 \text { months } \\
\text { (median) }\end{array}$ & $\begin{array}{l}24.7 \% \text { vs. } 10.7 \% \\
\text { (HR } 0.44 ; 95 \% \mathrm{Cl}, 0.23-0.82, \mathrm{P}=0.01)\end{array}$ & $\begin{array}{l}9.3 \% \text { vs. } 4.2 \% \\
\text { (HR } 0.23 ; 95 \% \mathrm{Cl}, 0.09-0.80, P=0.02)\end{array}$ \\
\hline Choi et al. (20) & 640 & 48 months & $\begin{array}{l}12.6 \% \text { vs. } 2.3 \% \\
(\mathrm{HR} 0.263 ; 95 \% \mathrm{Cl}, 0.087-0.790, \mathrm{P}=0.017)\end{array}$ & - \\
\hline $\begin{array}{l}\text { DECISION-CTO } \\
\text { study (21) }\end{array}$ & 815 & 60 months & $25.1 \%$ vs. $26.3 \%(P=0.67)$ & - \\
\hline
\end{tabular}

MACE, major adverse cardiovascular event; OMT, optimal medical therapy; PCI, percutaneous coronary intervention; $\mathrm{HR}$, hazard ratio; $\mathrm{Cl}$, confidence interval.

\section{Importance of CTO recanalization}

An important consideration for PCI is achieving complete revascularization in patients with coronary artery disease. Complete revascularization is associated with improved mortality, major adverse coronary event (MACE) and stent thrombosis rates. In the SYNTAX population, incomplete revascularization was associated with increased mortality, MACE, and stent thrombosis at 4 years. Interestingly, the presence of CTO was demonstrated to be an independent predictor of incomplete revascularisation (9). Furthermore, in the overall SYNTAX population incomplete revascularisation (residual SYNTAX score $>8$ ) was associated with $35 \%$ increase in all-cause mortality at 5 years, whereas, those with complete or near complete (residual SYNTAX score $\leq 8)$ had comparable outcomes $(9,10)$.

\section{Long-term benefits of successful CTO PCI}

Experimental and clinical data suggest that collateral blood flow protects myocardium in patients with CTOs. It has been demonstrated that there is an inverse relationship between the extent of myocardial injury and presence of regional left ventricular dysfunction to the degree of collaterals on coronary angiography (11). In fact, well developed collaterals may reduce myocardial ischemia and facilitate maintenance of viable myocardium if antegrade flow is severely reduced or even absent (12). If the magnitude of viable myocardium in jeopardy is large, revascularization may allow complete recovery of myocardium and overall cardiac function, reduction of ventricular remodeling and prevention of fatal arrhythmias $(13,14)$.

However, there has been a growing pool of evidence in recent times suggesting that revascularisation of nonCTO stable coronary artery disease might offer limited advantages in comparison to medical therapy $(15,16)$. In CTO patients, whether CTO PCI confers long-term clinical benefits remains unclear. Numerous studies have compared optimal medical therapy (OMT) versus PCI in CTO populations-the majority of these retrospective studies have not demonstrated improved clinical outcomes (Table 1) (17-20). In addition, the recently presented data from DECISION-CTO study of randomized patients to CTO-PCI + OMT $(\mathrm{n}=417)$ or OMT $(\mathrm{n}=398)$ demonstrated MACE at 3 years was $20.6 \%$ vs. $19.6 \%, \mathrm{P}=0.008$ (noninferiority) and MACE at 5 years was $26.3 \%$ vs. $25.1 \%$, $\mathrm{P}=0.67$ (21). This is the largest randomized trial comparing CTO PCI to OMT to date, and although it did not show difference in outcomes, there are a number of study limitations that may have skewed outcomes. These were namely: the trial was stopped prematurely due to difficulty in enrolling patients, the estimated sample size was 1,284 but only 815 were included; there was non-negligible cross-cover, $18.1 \%$ from OMT to PCI arm and $15.6 \%$ from PCI arm to OMT; and periprocedural myocardial infarction was included in the primary endpoint favoring the OMT arm of study (21).

\section{Dedicated scoring to predict CTO PCI outcomes}

There are numerous models for predicting the probability 
A

\begin{tabular}{|c|c|c|}
\hline $\begin{array}{l}\text { Entry shape } \\
\text { Tapered/blunt }\end{array}$ & $\begin{array}{l}\text { Entry with any tapered tip or dimple } \\
\text { indicating direction of true lumen is } \\
\text { categorized as "tapered" }\end{array}$ & $\begin{array}{l}\text { Tapered: } 0 \\
\text { Blunt: } 1\end{array}$ \\
\hline Calcification & $\begin{array}{l}\text { Regardless of severity, } 1 \text { point } \\
\text { assigned if any evident calcification is } \\
\text { detected within the CTO segment }\end{array}$ & $\begin{array}{l}\text { Absence: } 0 \\
\text { Presence: } 1\end{array}$ \\
\hline Bending $>45^{\circ}$ & $\begin{array}{l}\text { One point is assigned if bending }>45^{\circ} \\
\text { is detected within the CTO segment }\end{array}$ & $\begin{array}{l}\text { Absence: } 0 \\
\text { Presence: } 1\end{array}$ \\
\hline Occlusion length & $\begin{array}{l}\text { Using good collateral images, try to } \\
\text { measure "true" distance of occlusion }\end{array}$ & $\begin{array}{l}<20 \mathrm{~mm}: 0 \\
\geq 20 \mathrm{~mm}: 1\end{array}$ \\
\hline Re-try lesion & $\begin{array}{l}\text { Is this re-try (2nd at-tempted) lesion } \\
\text { (previously failed lesion)? }\end{array}$ & $\begin{array}{l}\text { No: } 0 \\
\text { Yes: } 1\end{array}$ \\
\hline \multicolumn{2}{|c|}{ Category of difficulty (total points) } & \\
\hline Easy: 0 & Intermediate: 1 & Total points \\
\hline Difficulty: 2 & Very difficult: $\geq 3$ & \\
\hline
\end{tabular}

B

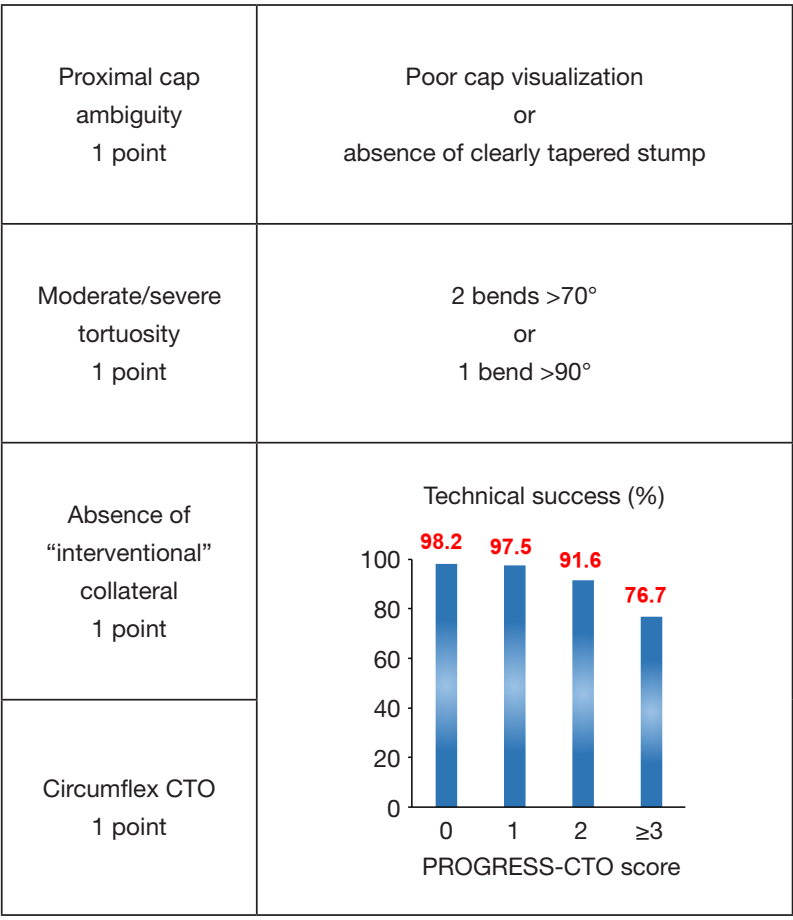

Figure $1 \mathrm{~J}$-CTO score and PROGRESS score. (A) J-CTO score; (B) PROGRESS score. CTO, chronic total occlusion.

of technical success for CTO PCI. The two most widely adopted are the J-CTO (multicenter CTO registry in Japan) and PROGRESS CTO (Prospective Global Registry for the Study of Chronic Total Occlusion Intervention) scores. These provide simple and convenient indices to evaluate probability of successful treatment for CTO on a lesion-by-lesion basis.

The J-CTO score was developed using a multicenter CTO registry from Japan that included 494 native CTO lesions. The end point was successful guidewire crossing within 30 minutes. The authors demonstrated that independent predictors included calcification, bending $>45$ degrees, blunt stump, occlusion length $>20 \mathrm{~mm}$, and previously failed lesion; these formed the predictive variables for the J-CTO score, a score of 1 for each variable with a maximum of 5 (Figure $1 A$ ) (22).

The PROGRESS CTO score was developed to predict technical success based on an international multicenter study that included 781 CTO PCIs (8). Variables strongly associated with technical success in multivariable analysis were assigned 1 point, and a 4-point score was developed from summing all points (Figure 1B). The PROGRESS CTO score included proximal cap ambiguity, moderate/ severe tortuosity, circumflex artery CTO, and absence of "interventional" collaterals.

\section{Conventional and contemporary CTO PCI techniques (Table 2)}

Initially, CTO PCI was performed with an antegrade wiring approach. Due to the hard tissue in CTO lesions and the complex lesion morphology, wire(s) could easily cross the subintimal/subadventitial space. Consequently, the initial rate of successful recanalization was low $(60-70 \%)$, with complications including coronary perforation, extended dissection-compromising SB or impairing distal collateral flow-and myocardial infarction. In order to improve the antegrade approach, wire-based antegrade dissection and re-entry (ADR) technique was developed. In 2005, Colombo et al. introduced subintimal tracking and re-entry (STAR) technique (Figure 2A) (23). Briefly, the STAR technique creates a subintimal cleavage plane by advancing a hydrophilic wire with a J-loop configuration (i.e., knuckle wire) to allow a blunt dissection along to the vessel architecture, then aims to re-enter the distal true lumen. The STAR technique was attributed with a higher successful 


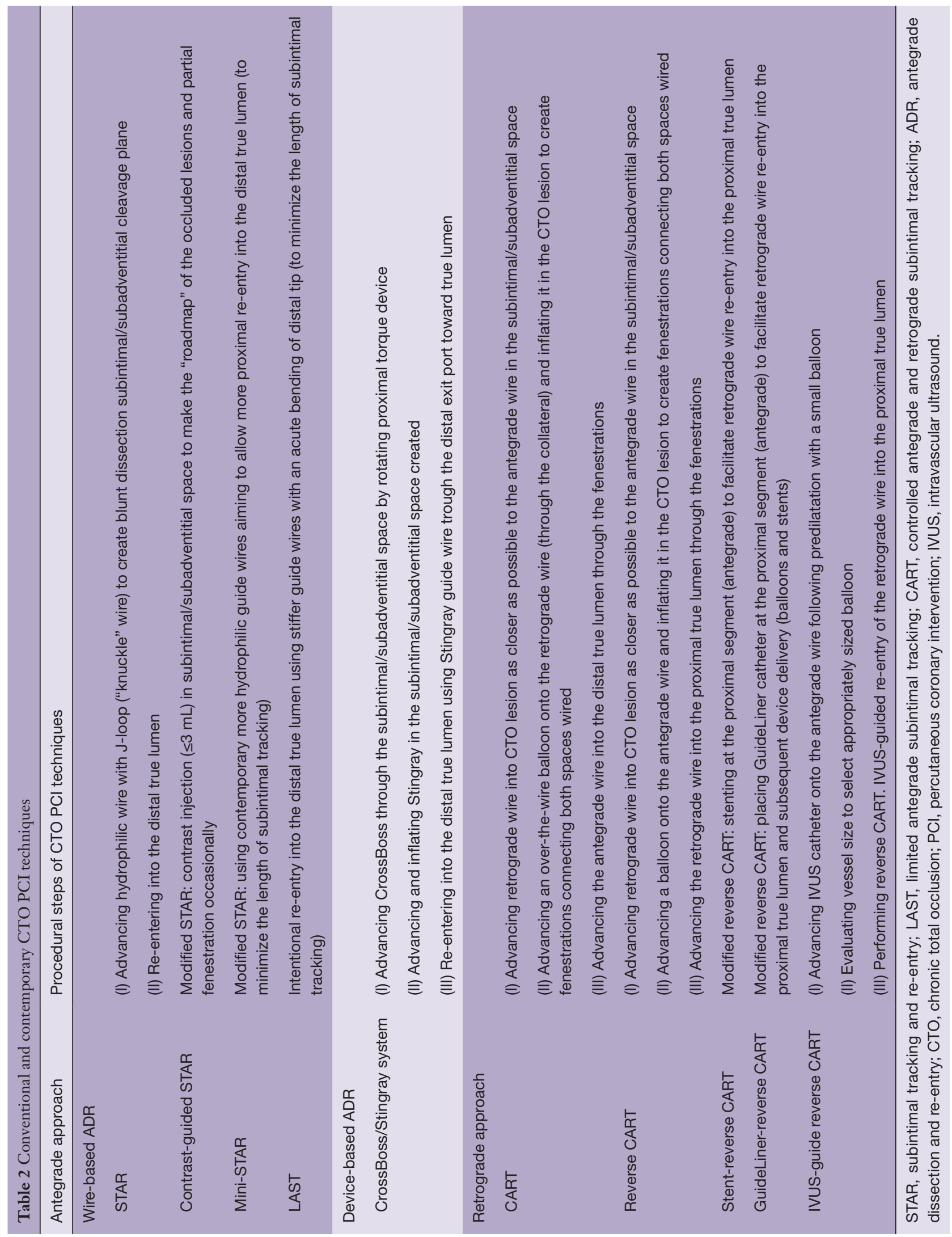


A

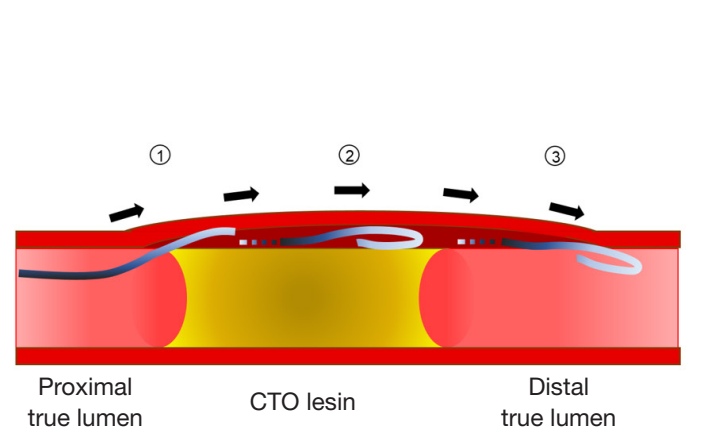

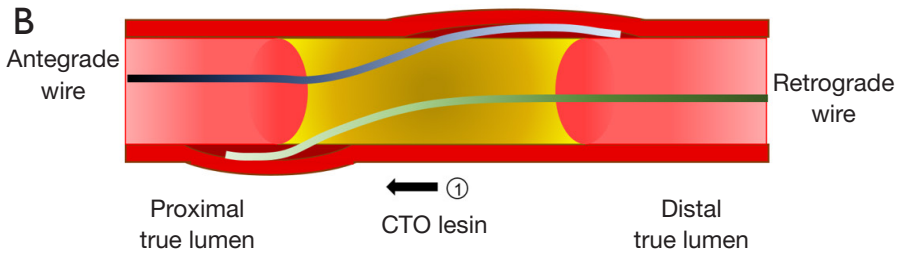

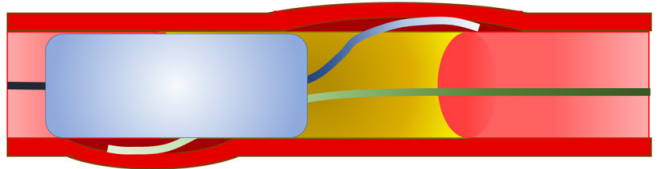

(2)

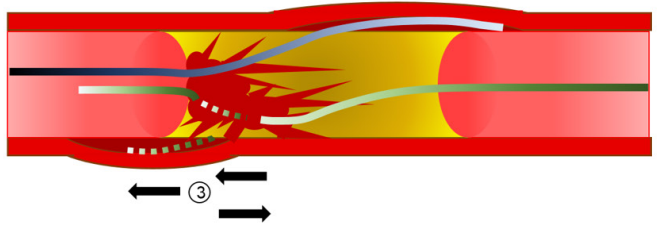

Figure 2 Illustrations of STAR technique and reverse CART technique. (A) STAR technique; (B) reverse CART technique. STAR, subintimal tracking and re-entry; CART, controlled antegrade and retrograde subintimal tracking; CTO, chronic total occlusion.

recanalization rate $(97 \%)$, however, it was associated with high rates of restenosis (52\% at 5 -month follow-up) (23). To overcome the limitations of the technique, several modified STAR techniques were developed (contrast-guided STAR, mini-STAR), resulting in better clinical outcomes $(24,25)$. However, wire-based ADR techniques inherently have limitations; namely: (I) disrupting vessel architecture; (II) requiring longer stenting to seal extended dissection; (III) compromising side branch(es) (SBs), resulting in poor run-off and lower long-term patency (final TIMI flow $<3$ with ADR techniques: 4-19\%).

As an alternate approach designed in an effort to overcome the limitations of antegrade approach including $\mathrm{ADR}$, the retrograde approach was developed by Japanese CTO operators (26), which improved procedural success-especially in complex cases with development of specific devices (microcatheters and guide wires). The greatest advantage of the retrograde approach is ensuring distal vessel true lumen wiring without extensive distal dissection. Although the retrograde approach would have the same limitations as an antegrade approach with wire escalation technique alone, utilizing the dissection and reentry technique combined with the antegrade approach could facilitate successful CTO recanalization while minimizing subintimal/subadventitial tracking. Reverse controlled antegrade and retrograde subintimal tracking (CART) is currently the most promising technique used in the retrograde approach (Figure 2B) (27). Briefly, both antegrade and retrograde wires are advanced as close as possible each other in the CTO lesion (independent of the true lumen or subintimal/subadventitial space). A balloon on the antegrade wire is then inflated to make fenestrations between the spaces where both wires are placed. This allows the retrograde wire to cross the proximal true lumen. This technique has contributed to dramatically improve procedural success rates, especially in high complexity cases. The technique has also born further derivatives, with development of several modified techniques [stent-reverse CART, intravascular ultrasound (IVUS)-guide reverse CART, etc.] (28-30).

As a novel technique in the antegrade approach, devicebased ADR has been recently introduced. CrossBoss (Boston Scientific, Marlborough, MA, USA) is a microcatheter with a $1-\mathrm{mm}$ metallic blunt tip that is advanced through the subintimal/subadventitial space by a rotating proximal torque device. Re-entry is attempted using the Stingray 
balloon catheter (Boston Scientific) following the CrossBoss approach. The Stingray catheter is a $2.5 \mathrm{~mm} \times 10 \mathrm{~mm}$ balloon that has a flat shape with two exit side ports (oriented at $180^{\circ}$ opposite to each other). At low pressure, this device could be inflated in the subintimal/subadventitial space as wrapping the inside true lumen from the outside, and reentry using dedicated stiff wire (Stingray guide wire) is subsequently attempted through the one exit port toward true lumen (http://www.bostonscientific.com) (31). In the previous study, the CrossBoss/Stingray system facilitated successful true lumen re-entry in $87 \%$ in cases without increasing complications, compared with historical controls using other CTO devices (31). In comparison to other wirebased ADR techniques, the CrossBoss/Stingray system has also shown significantly lower adverse cardiac events at 2-year follow-up (32).

\section{Algorithm}

Two main algorithms have been developed to utilize the techniques discussed so far. The hybrid strategy was developed by North American operators in 2012 (Figure 3A) (33). The concept is to switch approach or technique to another with rapidity in cases with low likelihood of success. The algorithm starts with angiographic CTO morphological assessment with dual injections, consisting of four factors: (I) proximal cap ambiguity; (II) distal vessel condition (size, degree of diseased, presence of bifurcation); (III) presence of suitable collaterals for a retrograde approach; (IV) lesion length $>20 \mathrm{~mm}$. According to these evaluations, initial approach is determined (antegrade/retrograde), followed by technical strategies based on operator skill or equipment available. Importantly, in order to increase chance of attempting another strategy (approach or technique), operators should not persist with their initial strategies when they encounter difficulty to proceed, consequently resulting in higher risk of complications, high dose contrast use, or radiation exposure. It has been reported that the Hybrid strategy is an effective (procedure success: 90.5\%) and safe (cardiac tamponade: $0.4 \%$, Q-wave myocardial infarction: $1.0 \%$, death: $0.4 \%$ ) strategy when compared with conventional approaches (34).

The Asia-Pacific algorithm was developed by experienced Japanese CTO operators (Figure 3B) (35). Notably, they firstly recommend appropriate case selection for each CTO operator (individual experience) based on J-CTO score (case difficulty) to improve procedural success. Furthermore, it differs from the Hybrid strategy by recommending that intravascular imaging guidance is utilized to overcome proximal cap ambiguity and difficulty with true lumen wiring, which contributes to limit attempts of the dissection re-entry techniques as the last resort ("true to true" philosophy). It also recommends when an operator should consider stopping the procedure with pre-specified cutoff values regarding contrast dose used $>$ estimated glomerular filtration rate $(\mathrm{eGFR}) \times 3.7(\mathrm{~mL})$, procedure time $>3$ hours, or radiation exposure $>5$ Gy (Air Kerma). Excellent results of CTO PCI in the Asian region have been previously reported, and the future feasibility, safety, and efficacy of this novel algorithm developed should be prospectively evaluated.

These algorithms establish CTO PCI concepts and techniques systematically, allowing CTO PCI to be widely performed in a more effective and safer manner. It has been considered that CTO PCI is a most complex procedure that should only be undertaken by experienced operators; however, these systematic algorithms facilitate reproducibility of this complex PCI, contributing to it been adopted more widely with utilization of modern learning along the line of "share, teach, and learn" (e.g., live demonstration, on-site proctoring, etc.).

\section{Clinical results of CTO PCI}

Clinical results after CTO PCI from large registries are summarized in Table 3 (36-42). As already mentioned, with development of dedicated devices and techniques, higher rates of procedural success and favorable clinical outcomes have been achieved worldwide, which could be further improved utilizing systematic algorithms.

\section{Specific subgroups: diabetes mellitus (DM), and elderly patients}

Although DM is one of the comorbidities associated with higher mortality independently, it also reflects excessively advanced atherosclerosis burden. From multicenter prospective registry, Sanguineti et al. reported that, in DM cohort, successful CTO PCI was associated with improved long-term clinical outcomes (median: 4.2 years), especially reducing cardiac mortality $(13.0 \%$ in successful PCI $v s$. $31.0 \%$ in failed PCI, $\mathrm{P}<0.001$ ) (43). Salisbury et al. reported that, after adjusting for prior coronary artery bypass grafting (CABG) and lesion complexity, there were no differences in procedural success and complication rates in CTO PCI 

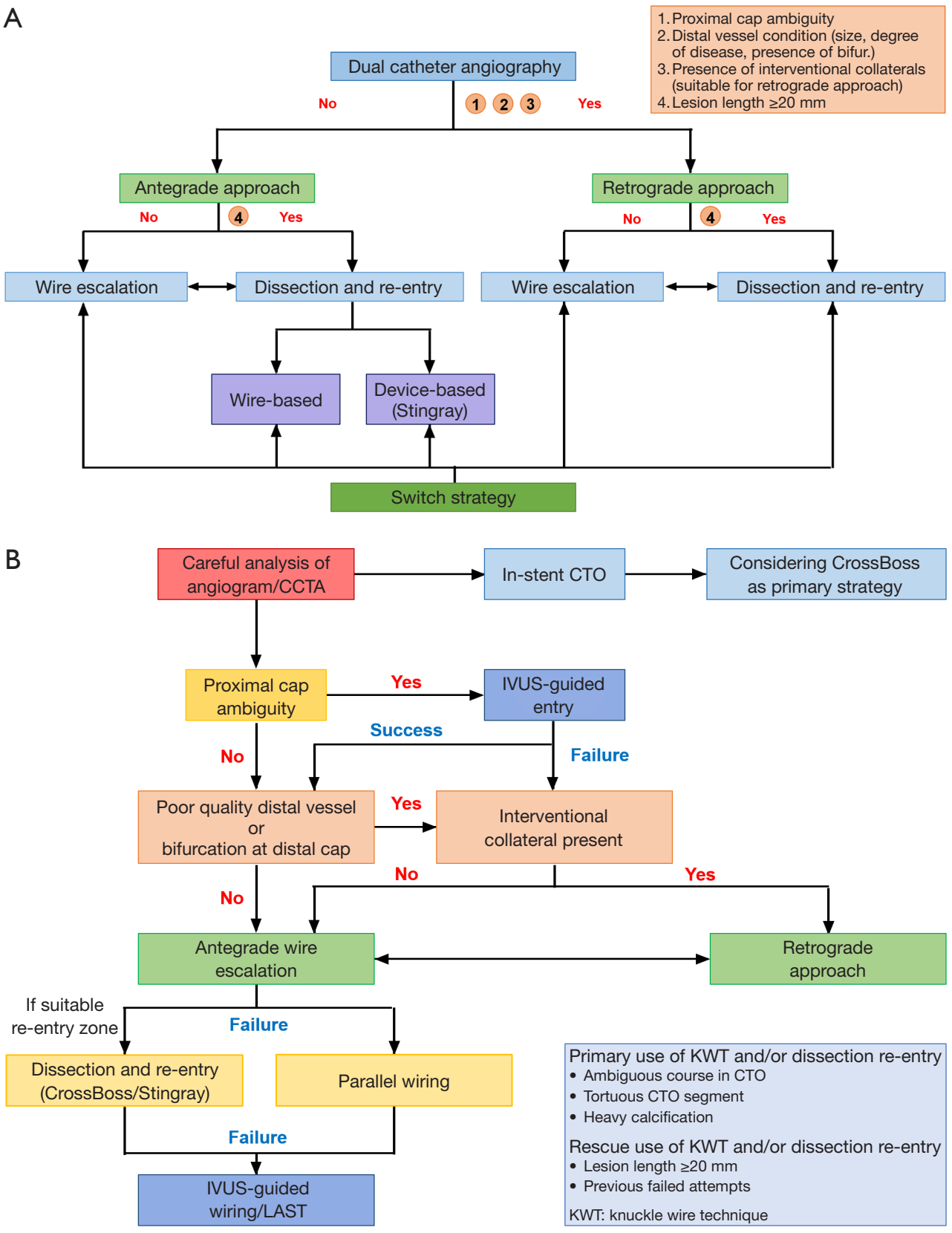

Figure 3 Contemporary CTO PCI algorithm. (A) Hybrid algorithm; (B) Asian-Pacific algorithm. CTO, chronic total occlusion; PCI, percutaneous coronary intervention; IVUS, intravascular ultrasound; LAST, limited antegrade subintimal tracking; CCTA, coronary computed tomography angiography.

between DM and non-DM patients (44). These reports would support the feasibility, safety and efficacy of CTO PCI for DM patients.

There is a paucity of data on CTO PCI in elderly patients, primarily due to the presence of multiple comorbidities that make these patients high risk, and hence inappropriate for management. A single center study reported that procedural success and complication rates in elderly patients ( $>75$ years) were similar to younger patients ( $<75$ years), and successful CTO PCI in elderly patients was significantly associated with lower cardiac death at 3-year follow-up (45). Similar results with 5-year follow-up were 


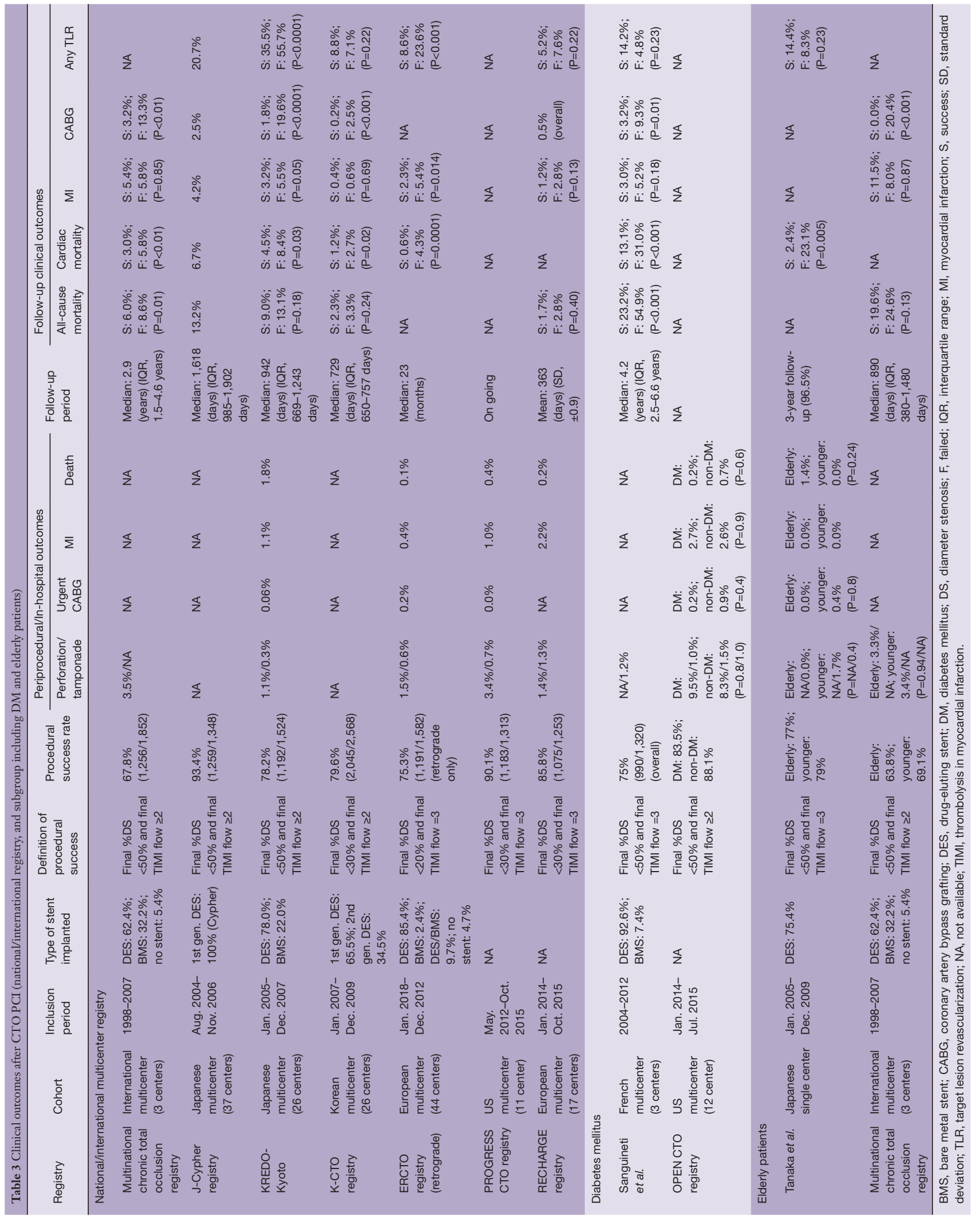


reported from an international multicenter registry (46). As surgical risk is higher in elderly patients, CTO PCI should be considered in this group and especially in patients who are deemed to have prohibitive surgical risk.

\section{When would interventionists call cardiac surgeons?}

\section{Multivessel disease (MVD)}

For patients with MVD and high SYNTAX score (especially three-vessel disease, and SYNTAX sore $>32$ ), complete revascularization with CABG is recommended in the current guidelines (class I) $(47,48)$. The presence of CTO may not affect the technical complexity nor clinical outcomes in CABG $(49,50)$, whereas, for PCI, the CTO lesion complexity, especially unfavorable lesion morphology for PCI (severe tortuosity or calcification, etc.), would significantly impact on not only procedural success, but also clinical outcomes. In order to achieve the best possible results for patients, an appropriate strategy for each case should be discussed by the Heart team.

\section{CTO PCI failure case}

When several attempts of CTO PCI have failed, interventionists should consider surgical revascularization in cases with significant residual ischemia or persistent anginal symptoms associated with the CTO lesions. As shown in Table 3, the cumulative rates of CABG for the CTO lesion after failed PCI were $2.5 \%$ to $19.6 \%$ during mid- to long-term follow-up. In addition, an important consideration is that the quality of vessels adjacent to the CTO lesions may have changed as a result of failed prior PCI attempts (e.g., extended dissections, collapsed distal vessel with impaired collateral flow, compromised $\mathrm{SBs}$, etc.). In order to determine appropriate grafting sites, coronary angiography at the previous PCI should be carefully reviewed by the Heart team and repeat preoperative angiography (either CT or catheterization) would be also recommended, if CABG is planned after a certain interval from the prior PCI.

\section{Complications}

During CTO PCI-with the exception of urgent rescue CABG-complications, especially coronary perforation, would be the most common scenario when interventionists need to call cardiac surgeons. From a meta-analysis including 18,061 patients of 65 studies, coronary perforation and cardiac tamponade during CTO PCI has been reported to occur in $2.9 \%$ and $0.3 \%$ of patients, respectively (51). It is sometimes difficult to manage coronary perforation with a conservative or percutaneous strategy (balloon occlusion, coiling etc.), because the perforated site is basically located within or distal to the non-recanalized CTO or supplied by multiple collaterals.

\section{When would PCI be required after CABG?}

It has been reported that $99.8 \%$ successful revascularization was achieved in minimally invasive CABG to LAD CTO using internal mammary artery, with $90.5 \%$ overall survival rates estimated at 5 years follow-up, comparable to the non-CTO LAD lesion (90.4\%) $(\mathrm{P}=0.91)(49)$. On the other hand, saphenous vein graft (SVG) is inferior in longterm patency (approximately $50 \%$ at 10 years); however, it has been used widely for the cases with MVD, aiming for complete revascularization. As a result, in clinical settings, interventionists sometimes encounter failed SVG to the lesions including CTO, especially in RCA or left circumflex artery (LCx). Due to the high surgical risk (e.g., age, comorbidities, etc.) or technical complexity (e.g., postoperation adhering, presence of previous grafts, etc.) of redo CABG, interventionists need to consider PCI for the native CTO lesions. However, CTOs in post-CABG exhibit extensive calcification and negative remodeling, compared with CTOs in non-CABG (52), thus PCI for such lesions is more challenging. Consequently, CTO PCI in postCABG patients is associated with lower success rates and worse clinical outcomes at follow-up (median: 377 days), compared to those in non-CABG patients (53).

\section{Integrated management strategies involving cardiac surgeon and interventional cardiologist}

In recent years, for the patients with MVD, hybrid coronary revascularization (HCR) consisting of a LIMALAD anastomosis through minimally invasive direct coronary artery bypass (MIDCAB) plus PCI for remaining non-LAD lesions, has attracted much attention from both interventionists and cardiac surgeons. A previous randomized trial, encompassing 200 patients who were randomly assigned to either HCR or CABG, demonstrated no differences in the rates of death, myocardial infarction, stroke, major bleeding, or repeat revascularization at the 

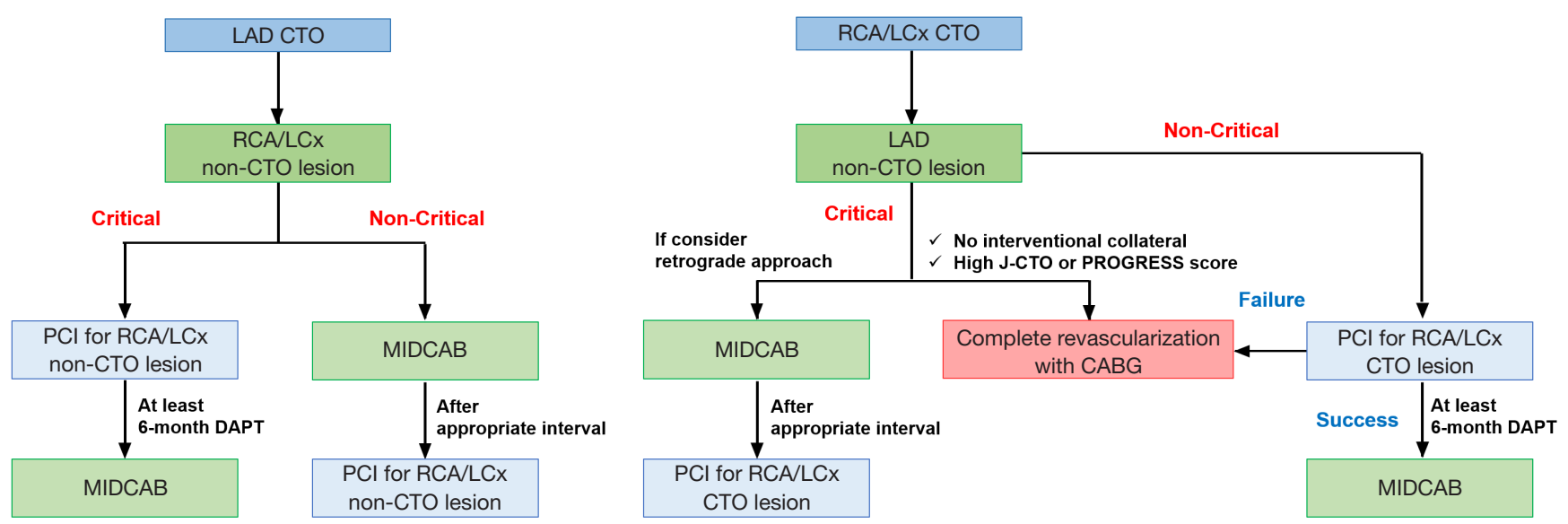

Figure 4 Hybrid coronary revascularization in patients with multivessel disease including CTO. CTO, chronic total occlusion; LAD, left anterior descending artery; RCA, right coronary artery; LCx, left circumflex artery; DAPT, dual antiplatelet therapy; MIDCAB, minimally invasive direct coronary artery bypass; PCI, percutaneous coronary intervention; CABG, coronary artery bypass grafting.

1-year follow-up (54). Despite these favorable results for HCR, it still remains a limited procedure $(0.5 \%$ of CABG performed in U.S. from 2011 to 2013) (55), primarily due to the following reasons: (I) there are limited patients who indicate HCR as the ideal management pathway (patients' comorbidities, anatomy, lesion location, etc.) and, (II) HCR is a technically demanding surgical procedure. Consequently, it has been reported that the general consensus among interventionists and surgeons in the 11 premier US cardiac surgical centers, regarding candidates for HCR, were achieved in approximately $10 \%$ of 6,669 consecutive coronary angiograms (56). Furthermore, regarding HCR for patients with MVD including a CTO lesion, there are numerous considerations that need to be addressed; these are best done by the Heart team: (I) the location of CTO lesion(s) (LAD or non-LAD); (II) the conditions of collateral(s); (III) the condition of donor artery(s). The possible strategy of HCR for these patients is outlined in Figure 4. Briefly, for patients with LAD CTO, MIDCAB would be performed first, followed by elective PCI to RCA/LCx, if they are stable and noncritical lesions. On the other hand, if these lesions are critical, primary PCI could be considered to guarantee perioperative safety during MIDCAB (at least 6-month dual antiplatelet therapy after PCI is mandatory). For the patients with non-LAD CTO, there are multiple factors which should be considered, as shown in Figure 4, and such cases are probably best managed with complete revascularization via either PCI or CABG alone, depending on the balance of risk and benefits for HCR.

\section{Conclusions}

There have been marked improvements in the feasibility and safety of CTO PCI, due to development of various techniques and dedicated devices. The establishment of systematic CTO PCI algorithms would enable interventionists to share, teach, and learn this technically challenging field in a broader context. This would also contribute to further improving clinical outcomes. Considering the importance of complete revascularization, in order to achieve the best benefits of CTO recanalization for patients, the Heart team requires appropriate patient selection and treatment strategy for each patient.

\section{Acknowledgements}

None.

\section{Footnote}

Conflicts of Interest: The authors have no conflicts of interest to declare.

\section{References}

1. Stone GW, Kandzari DE, Mehran R, et al. Percutaneous recanalization of chronically occluded coronary arteries: A consensus document: Part i. Circulation 2005;112:2364-72.

2. Fefer P, Knudtson ML, Cheema AN, et al. Current perspectives on coronary chronic total occlusions: The 
canadian multicenter chronic total occlusions registry. J Am Coll Cardiol 2012;59:991-7.

3. Tsai TT, Stanislawski MA, Shunk KA, et al. Contemporary incidence, management, and long-term outcomes of percutaneous coronary interventions for chronic coronary artery total occlusions: Insights from the va cart program. JACC Cardiovasc Interv 2017;10:866-75.

4. Azzalini L, Torregrossa G, Puskas JD, et al. Percutaneous revascularization of chronic total occlusions: Rationale, indications, techniques, and the cardiac surgeon's point of view. Int J Cardiol 2017;231:90-6.

5. Morino Y, Kimura T, Hayashi Y, et al. In-hospital outcomes of contemporary percutaneous coronary intervention in patients with chronic total occlusion insights from the $\mathrm{j}$-cto registry (multicenter cto registry in japan). JACC Cardiovasc Interv 2010;3:143-51.

6. Galassi AR, Tomasello SD, Reifart N, et al. In-hospital outcomes of percutaneous coronary intervention in patients with chronic total occlusion: insights from the ERCTO (European Registry of Chronic Total Occlusion) registry. EuroIntervention 2011;7:472-9.

7. Wilson WM, Walsh SJ, Yan AT, et al. Hybrid approach improves success of chronic total occlusion angioplasty. Heart 2016;102:1486-93.

8. Christopoulos G, Kandzari DE, Yeh RW, et al. Development and validation of a novel scoring system for predicting technical success of chronic total occlusion percutaneous coronary interventions: The progress cto (prospective global registry for the study of chronic total occlusion intervention) score. JACC Cardiovasc Interv 2016;9:1-9.

9. Farooq V, Serruys PW, Garcia-Garcia HM, et al. The negative impact of incomplete angiographic revascularization on clinical outcomes and its association with total occlusions: The syntax (synergy between percutaneous coronary intervention with taxus and cardiac surgery) trial. J Am Coll Cardiol 2013;61:282-94.

10. Farooq V, Serruys PW, Bourantas CV, et al. Quantification of incomplete revascularization and its association with five-year mortality in the synergy between percutaneous coronary intervention with taxus and cardiac surgery (syntax) trial validation of the residual syntax score. Circulation 2013;128:141-51.

11. Choi JH, Chang SA, Choi JO, et al. Frequency of myocardial infarction and its relationship to angiographic collateral flow in territories supplied by chronically occluded coronary arteries. Circulation 2013;127:703-9.

12. Steg PG, Kerner A, Mancini GB, et al. Impact of collateral flow to the occluded infarct-related artery on clinical outcomes in patients with recent myocardial infarction: A report from the randomized occluded artery trial. Circulation 2010;121:2724-30.

13. Wijns W, Vatner SF, Camici PG. Hibernating myocardium. N Engl J Med 1998;339:173-81.

14. Rogers WJ, Hood WP Jr, Mantle JA, et al. Return of left ventricular function after reperfusion in patients with myocardial infarction: Importance of subtotal stenoses or intact collaterals. Circulation 1984;69:338-49.

15. Mancini GBJ, Hartigan PM, Shaw LJ, et al. Predicting outcome in the courage trial (clinical outcomes utilizing revascularization and aggressive drug evaluation): Coronary anatomy versus ischemia. JACC Cardiovasc Interv 2014;7:195-201.

16. Al-Lamee R, Thompson D, Dehbi HM, et al. Percutaneous coronary intervention in stable angina (orbita): A double-blind, randomised controlled trial. Lancet 2018;391:31-40.

17. Hwang JW, Yang JH, Choi SH, et al. Optimal medical therapy may be a better initial strategy in patients with chronic total occlusion of a single coronary artery. Int J Cardiol 2016;210:56-62.

18. Yang JH, Kim BS, Jang WJ, et al. Optimal Medical Therapy vs. Percutaneous Coronary Intervention for Patients With Coronary Chronic Total Occlusion - A Propensity-Matched Analysis. Circ J 2016;80:211-7.

19. Jang WJ, Yang JH, Choi SH, et al. Long-term survival benefit of revascularization compared with medical therapy in patients with coronary chronic total occlusion and welldeveloped collateral circulation. JACC Cardiovasc Interv 2015;8:271-9.

20. Choi SY, Choi BG, Rha SW, et al. Percutaneous coronary intervention versus optimal medical therapy for chronic total coronary occlusion with well-developed collaterals. J Am Heart Assoc 2017;6. doi: 10.1161/JAHA.117.006357.

21. Park SJ. Optimal Medical Therapy With or Without Stenting For Coronary Chronic Total Occlusion DECISION-CTO. Available online: http://www.acc.org/ latest-in-cardiology/clinical-trials/2017/03/17/08/40/ decision-cto

22. Morino Y, Abe M, Morimoto T, et al. Predicting successful guidewire crossing through chronic total occlusion of native coronary lesions within 30 minutes: The j-cto (multicenter cto registry in japan) score as a difficulty grading and time assessment tool. JACC Cardiovasc Interv 2011;4:213-21.

23. Colombo A, Mikhail GW, Michev I, et al. Treating chronic 
total occlusions using subintimal tracking and reentry: the STAR technique. Catheter Cardiovasc Interv 2005;64:407-11; discussion 412.

24. Galassi AR, Tomasello SD, Costanzo L, et al. Mini-star as bail-out strategy for percutaneous coronary intervention of chronic total occlusion. Catheter Cardiovasc Interv 2012;79:30-40.

25. Godino C, Latib A, Economou FI, et al. Coronary chronic total occlusions: Mid-term comparison of clinical outcome following the use of the guided-star technique and conventional anterograde approaches. Catheter Cardiovasc Interv 2012;79:20-7.

26. Surmely JF, Tsuchikane E, Katoh O, et al. New concept for cto recanalization using controlled antegrade and retrograde subintimal tracking: The cart technique. J Invasive Cardiol 2006;18:334-8.

27. Saito S. Different strategies of retrograde approach in coronary angioplasty for chronic total occlusion. Catheter Cardiovasc Interv 2008;71:8-19.

28. Sianos G, Karlas A. Tools \& Techniques: CTO--the retrograde approach. EuroIntervention 2011;7:285-7.

29. Mozid AM, Davies JR, Spratt JC. The utility of a guideliner catheter in retrograde percutaneous coronary intervention of a chronic total occlusion with reverse cart-the "capture" technique. Catheter Cardiovasc Interv 2014;83:929-32.

30. Rathore S, Katoh O, Tuschikane E, et al. A novel modification of the retrograde approach for the recanalization of chronic total occlusion of the coronary arteries intravascular ultrasound-guided reverse controlled antegrade and retrograde tracking. JACC Cardiovasc Interv 2010;3:155-64.

31. Whitlow PL, Burke MN, Lombardi WL, et al. Use of a novel crossing and re-entry system in coronary chronic total occlusions that have failed standard crossing techniques: Results of the fast-ctos (facilitated antegrade steering technique in chronic total occlusions) trial. JACC Cardiovasc Interv 2012;5:393-401.

32. Azzalini L, Dautov R, Brilakis ES, et al. Procedural and longer-term outcomes of wire- versus device-based antegrade dissection and re-entry techniques for the percutaneous revascularization of coronary chronic total occlusions. Int J Cardiol 2017;231:78-83.

33. Brilakis ES, Grantham JA, Rinfret S, et al. A percutaneous treatment algorithm for crossing coronary chronic total occlusions. JACC Cardiovasc Interv 2012;5:367-79.

34. Christopoulos G, Menon RV, Karmpaliotis D, et al. The efficacy and safety of the "hybrid" approach to coronary chronic total occlusions: Insights from a contemporary multicenter us registry and comparison with prior studies. J Invasive Cardiol 2014;26:427-32.

35. Harding SA, Wu EB, Lo S, et al. A new algorithm for crossing chronic total occlusions from the asia pacific chronic total occlusion club. JACC Cardiovasc Interv 2017;10:2135-43.

36. Mehran R, Claessen BE, Godino C, et al. Long-term outcome of percutaneous coronary intervention for chronic total occlusions. JACC Cardiovasc Interv 2011;4:952-61.

37. Kato M, Kimura T, Morimoto T, et al. Comparison of five-year outcome of sirolimus-eluting stent implantation for chronic total occlusions versus for non-chronic total occlusion (from the j-cypher registry). Am J Cardiol 2012;110:1282-9.

38. Yamamoto E, Natsuaki M, Morimoto T, et al. Long-term outcomes after percutaneous coronary intervention for chronic total occlusion (from the credo-kyoto registry cohort-2). Am J Cardiol 2013;112:767-74.

39. Kim BK, Shin S, Shin DH, et al. Clinical outcome of successful percutaneous coronary intervention for chronic total occlusion: Results from the multicenter korean chronic total occlusion (k-cto) registry. J Invasive Cardiol 2014;26:255-9.

40. Galassi AR, Sianos G, Werner GS, et al. Retrograde recanalization of chronic total occlusions in europe: Procedural, in-hospital, and long-term outcomes from the multicenter ercto registry. J Am Coll Cardiol 2015;65:2388-400.

41. Danek BA, Karatasakis A, Karmpaliotis D, et al. Use of antegrade dissection re-entry in coronary chronic total occlusion percutaneous coronary intervention in a contemporary multicenter registry. Int J Cardiol 2016;214:428-37.

42. Maeremans J, Avran A, Walsh S, et al. One-year clinical outcomes of the hybrid cto revascularization strategy after hospital discharge: A subanalysis of the multicenter recharge registry. J Invasive Cardiol 2018;30:62-70.

43. Sanguineti F, Garot P, O'Connor S, et al. Chronic total coronary occlusion treated by percutaneous coronary intervention: Long-term outcome in patients with and without diabetes. EuroIntervention 2017;12:e1889-97.

44. Salisbury AC, Sapontis J, Grantham JA, et al. Outcomes of chronic total occlusion percutaneous coronary intervention in patients with diabetes: Insights from the open cto registry. JACC Cardiovasc Interv 2017;10:2174-81.

45. Tanaka Y, Takeshita S, Takahashi S, et al. Comparison of short- and long-term outcomes of percutaneous coronary 
intervention for chronic total occlusions between patients aged $\geq 75$ years and those aged $<75$ years. Am J Cardiol 2013;112:761-6.

46. Hoebers LP, Claessen BE, Dangas GD, et al. Long-term clinical outcomes after percutaneous coronary intervention for chronic total occlusions in elderly patients ( $\geq 75$ years): five-year outcomes from a 1,791 patient multi-national registry. Catheter Cardiovasc Interv 2013;82:85-92.

47. Levine GN, Bates ER, Blankenship JC, et al. 2011 ACCF/AHA/SCAI Guideline for Percutaneous Coronary Intervention: a report of the American College of Cardiology Foundation/American Heart Association Task Force on Practice Guidelines and the Society for Cardiovascular Angiography and Interventions. Circulation 2011;124:e574-651. Erratum in: Circulation 2012;125:e412. Dosage error in article text.

48. Authors/Task Force members, Windecker S, Kolh P, et al. 2014 ESC/EACTS Guidelines on myocardial revascularization: The Task Force on Myocardial Revascularization of the European Society of Cardiology (ESC) and the European Association for CardioThoracic Surgery (EACTS)Developed with the special contribution of the European Association of Percutaneous Cardiovascular Interventions (EAPCI). Eur Heart J 2014;35:2541-619.

49. Holzhey DM, Jacobs S, Walther T, et al. Is chronic total coronary occlusion a risk factor for long-term outcome after minimally invasive bypass grafting of the left anterior descending artery? Ann Thorac Surg 2010;89:1496-501.

50. Banerjee S, Master RG, Peltz M, et al. Influence of chronic total occlusions on coronary artery bypass graft surgical outcomes. J Card Surg 2012;27:662-7.

51. Patel VG, Brayton KM, Tamayo A, et al. Angiographic success and procedural complications in patients undergoing percutaneous coronary chronic total occlusion interventions: A weighted meta-analysis of 18,061 patients from 65 studies. JACC Cardiovasc Interv 2013;6:128-36.

52. Sakakura K, Nakano M, Otsuka F, et al. Comparison of pathology of chronic total occlusion with and without coronary artery bypass graft. Eur Heart J 2014;35:1683-93.

53. Azzalini L, Ojeda S, Karatasakis A, et al. Long-Term Outcomes of Percutaneous Coronary Intervention for Chronic Total Occlusion in Patients Who Have Undergone Coronary Artery Bypass Grafting vs Those Who Have Not. Can J Cardiol 2018;34:310-8.

54. Gąsior M, Zembala MO, Tajstra M, et al. Hybrid revascularization for multivessel coronary artery disease. JACC Cardiovasc Interv 2014;7:1277-83.

55. Harskamp RE, Brennan JM, Xian Y, et al. Practice patterns and clinical outcomes after hybrid coronary revascularization in the united states: An analysis from the society of thoracic surgeons adult cardiac database. Circulation 2014;130:872-9.

56. D'Ancona G, Vassiliades TA, Boyd WD, et al. Is hybrid coronary revascularization favored by cardiologists or cardiac surgeons? Heart Surg Forum 2002;5:393-5.
Cite this article as: Mitomo S, Demir OM, Colombo A, Nakamura S, Chieffo A. What the surgeon needs to know about percutaneous coronary intervention treatment of chronic total occlusions. Ann Cardiothorac Surg 2018;7(4):533-545. doi: 10.21037/acs.2018.06.04 